\title{
Complex dynamics of a discrete-time prey-predator system with Allee effect
}

Özlem Gümüş ${ }^{1}$

${ }^{1}$ Adiyaman University Faculty of Arts and Sciences

December 8, 2021

\begin{abstract}
In this paper, we investigate the stability and bifurcation of a discrete-time prey-predator system which is subject to an Allee effect on prey population. It is concluded that the system undergoes flip and Neimark- Sacker bifurcations in a small neigborhood of the unique positive fixed point which depends on the number of prey-predator. The chaotic behavior that emerges with Neimark-Sacker bifurcation is controlled by the OGY method and hybrid control method. Moreover, the numerical simulations are done to demonsrate the theoratical results.
\end{abstract}

\section{Hosted file}

Complex dynamics of prey-predator system with Allee effect.pdf available at https: //authorea.com/users/450090/articles/548492-complex-dynamics-of-a-discrete-time-preypredator-system-with-allee-effect

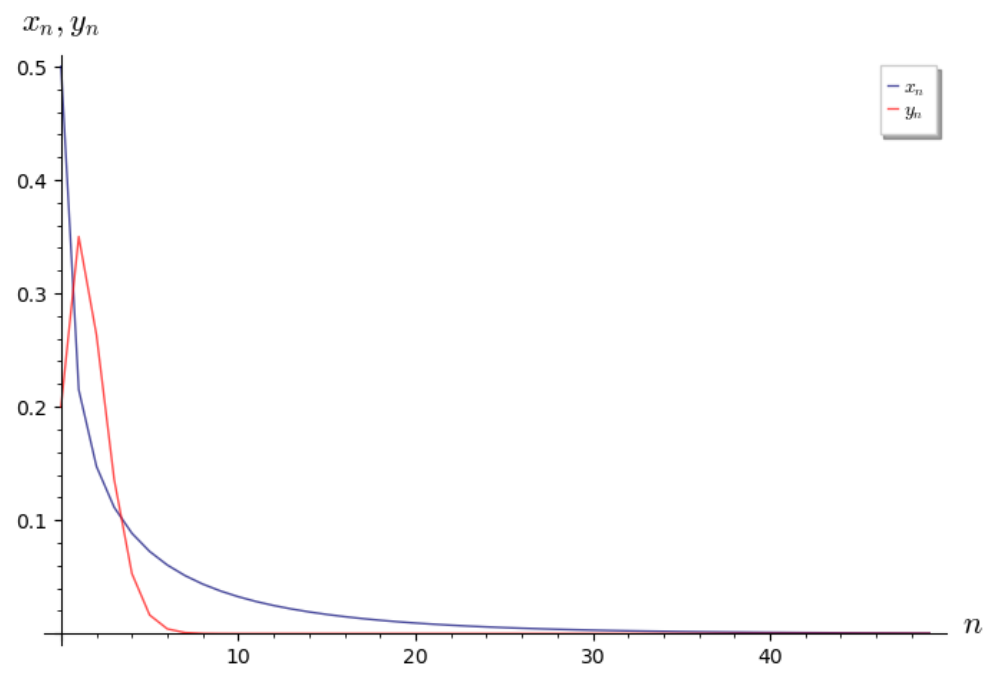



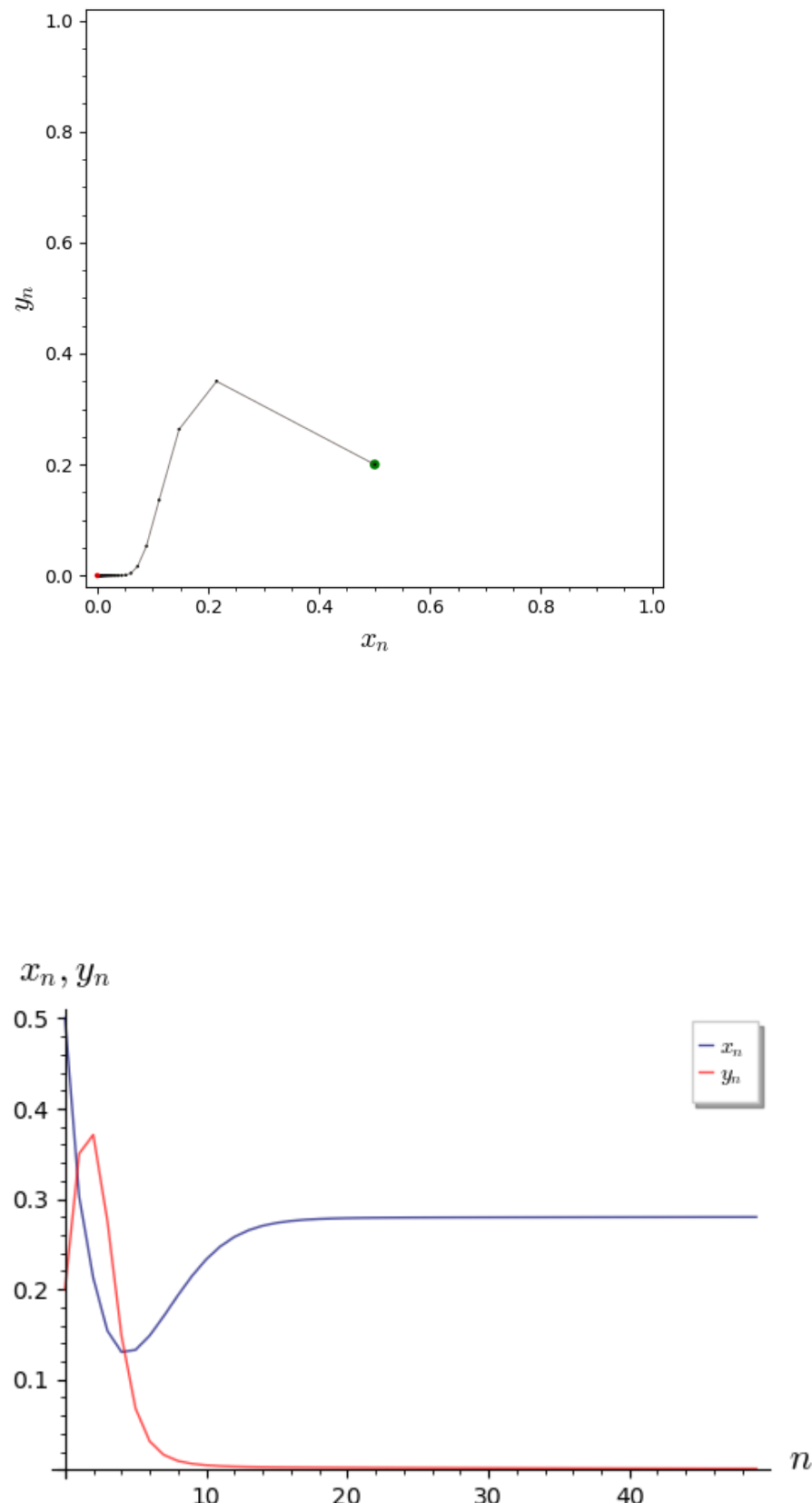

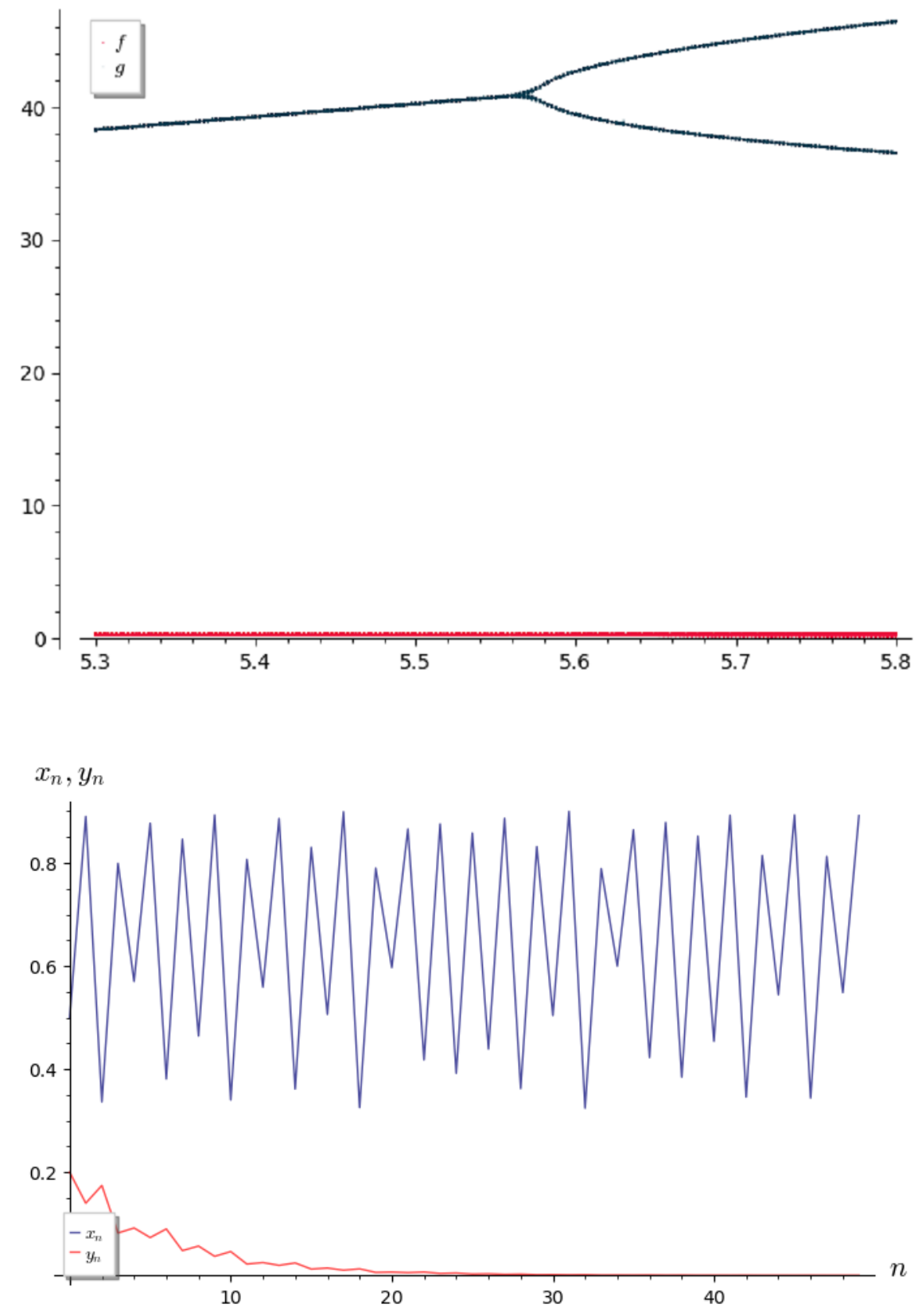


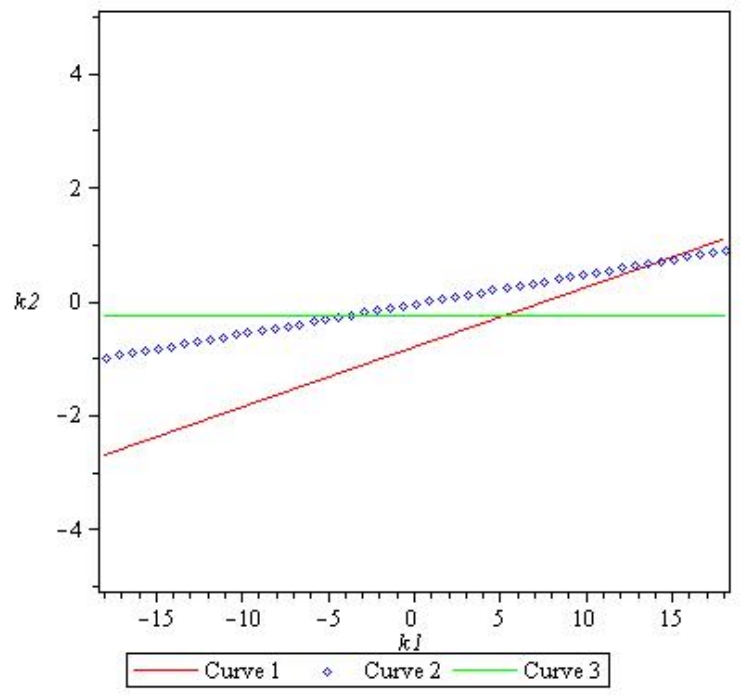



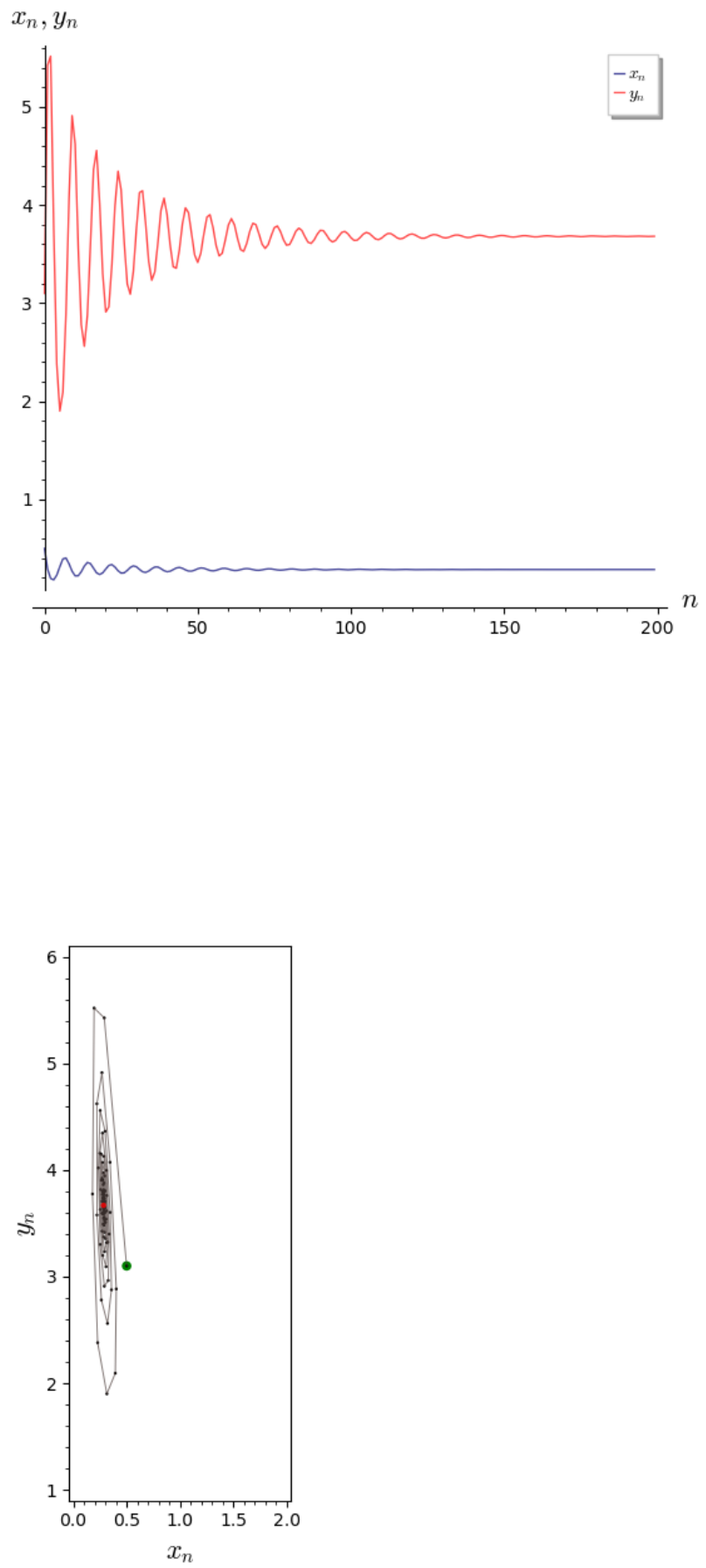

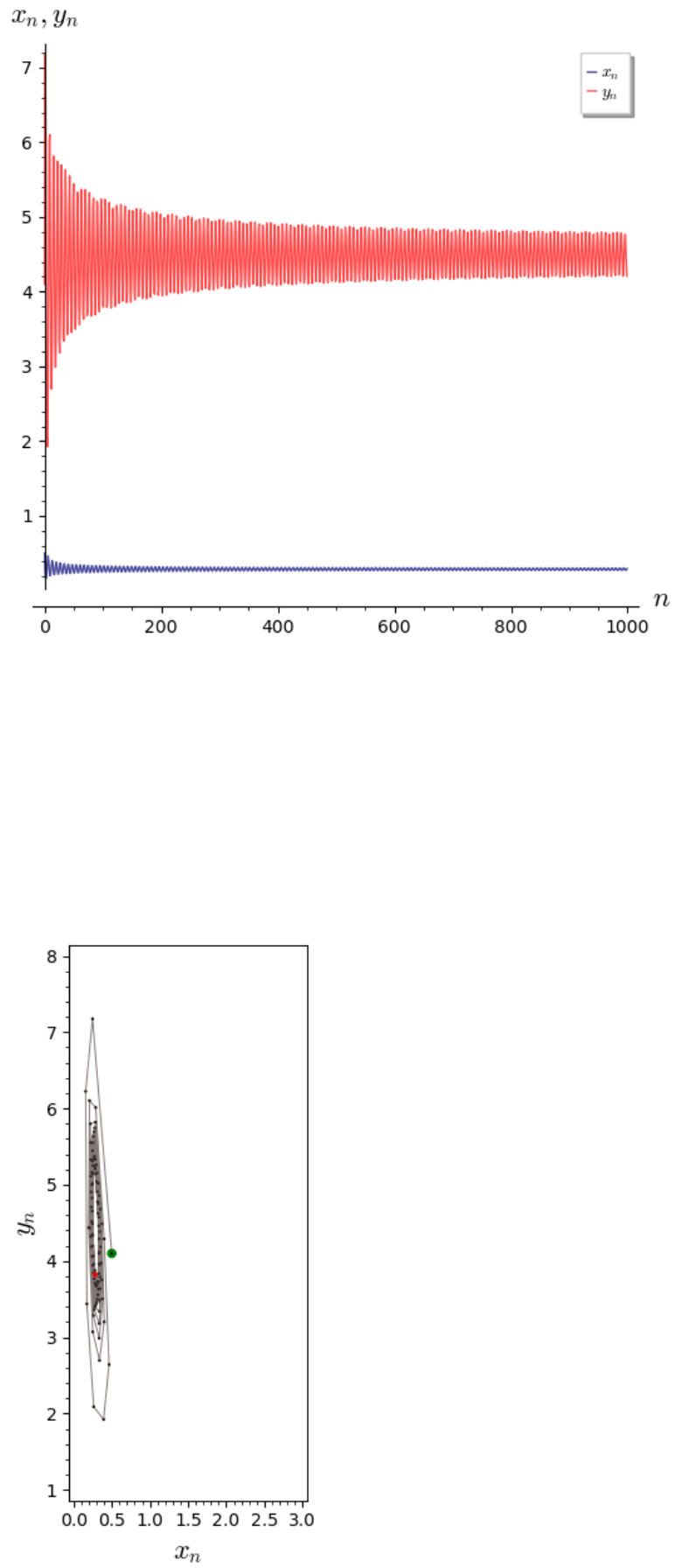

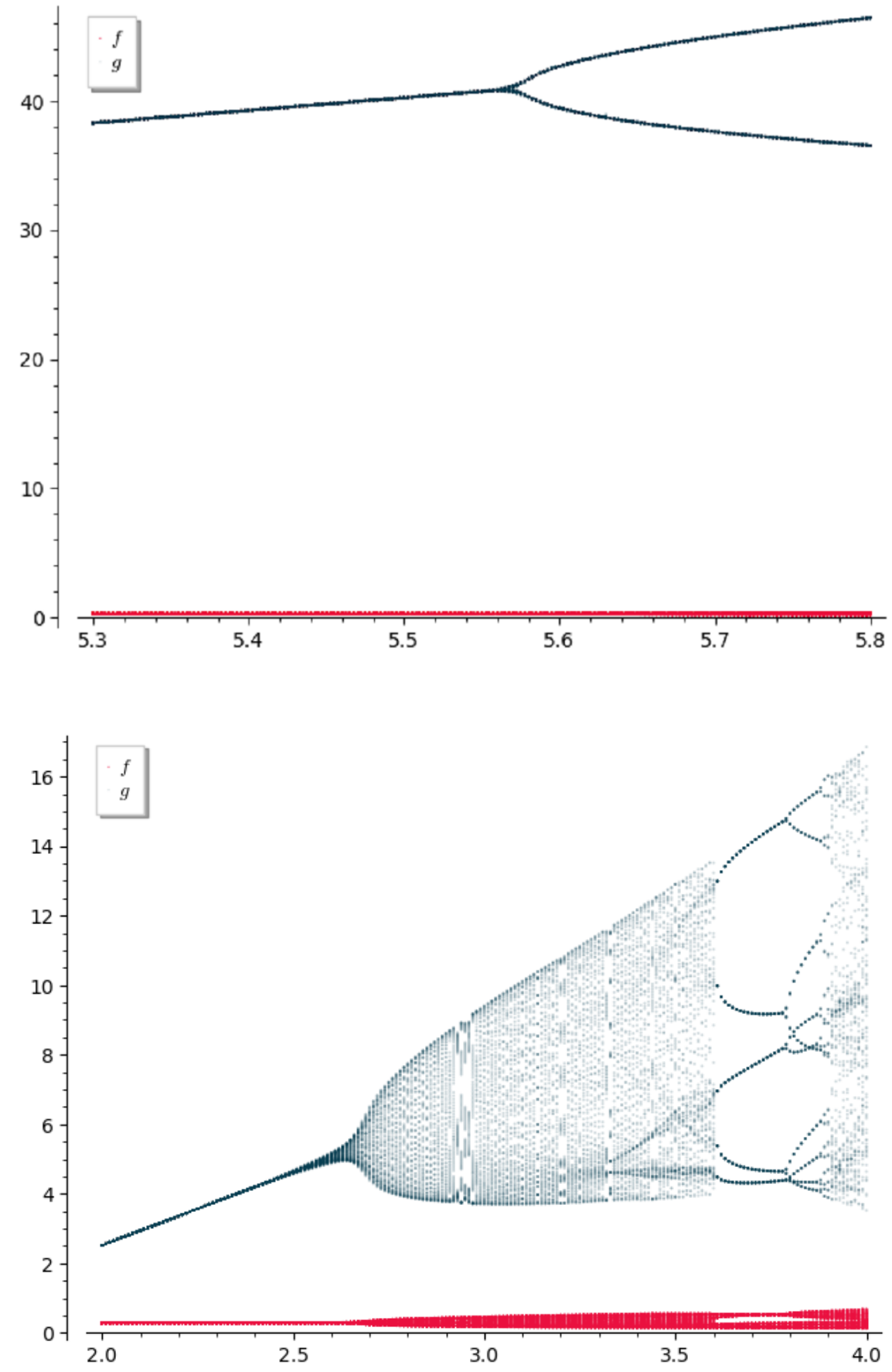

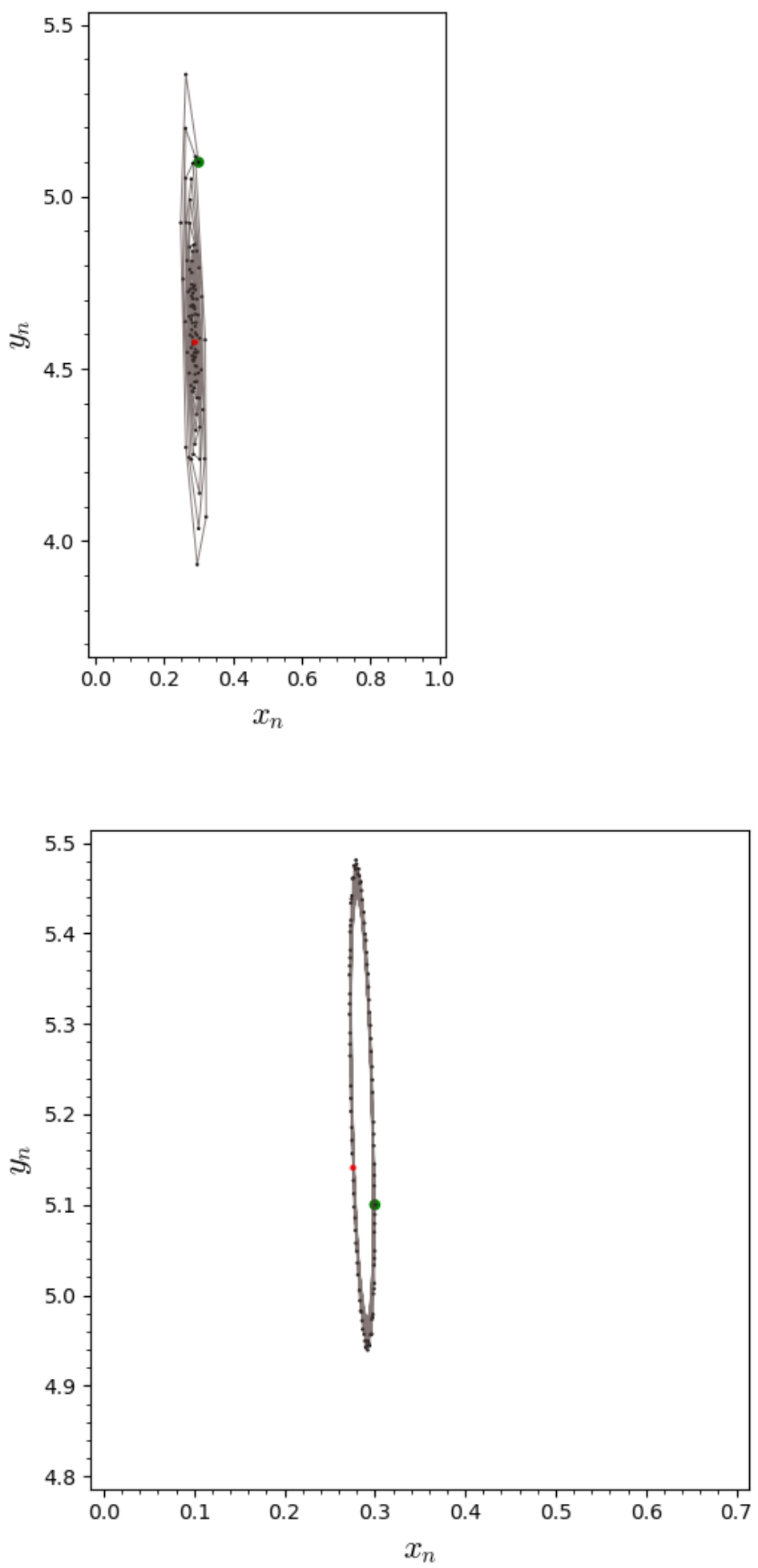


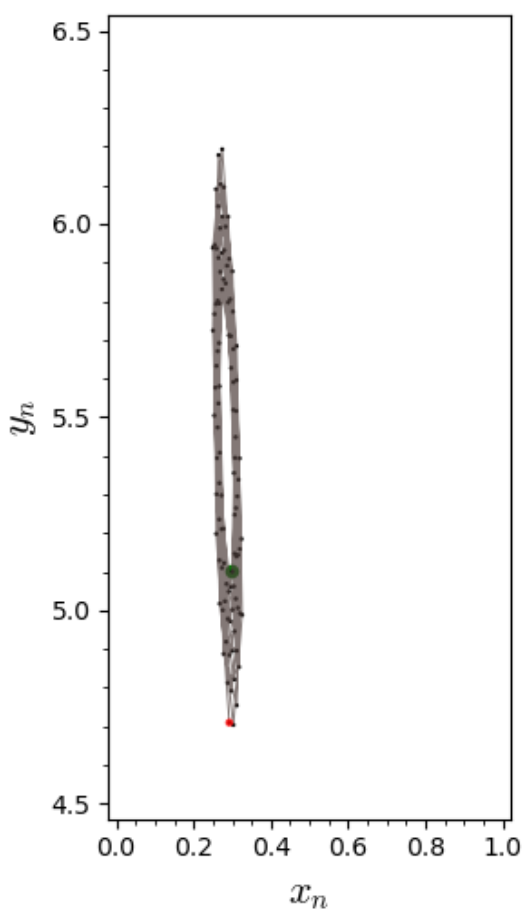




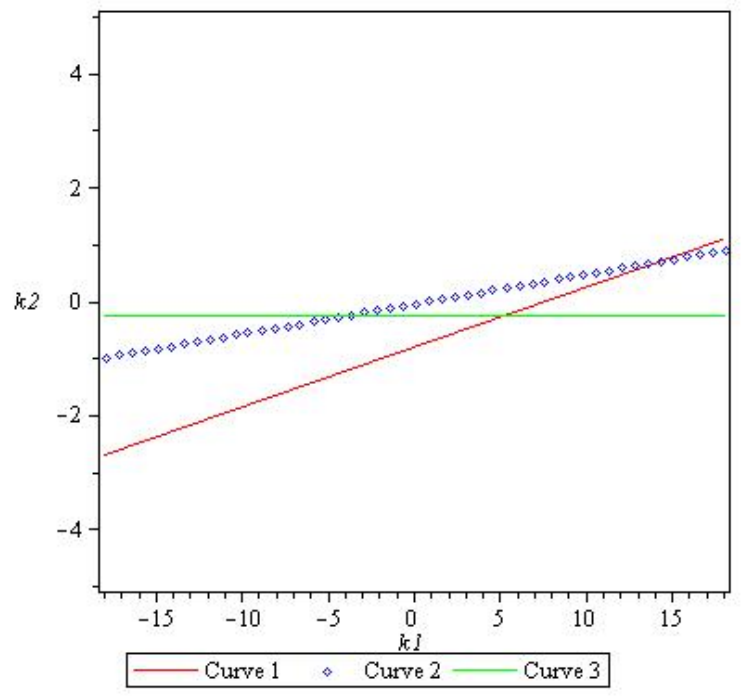




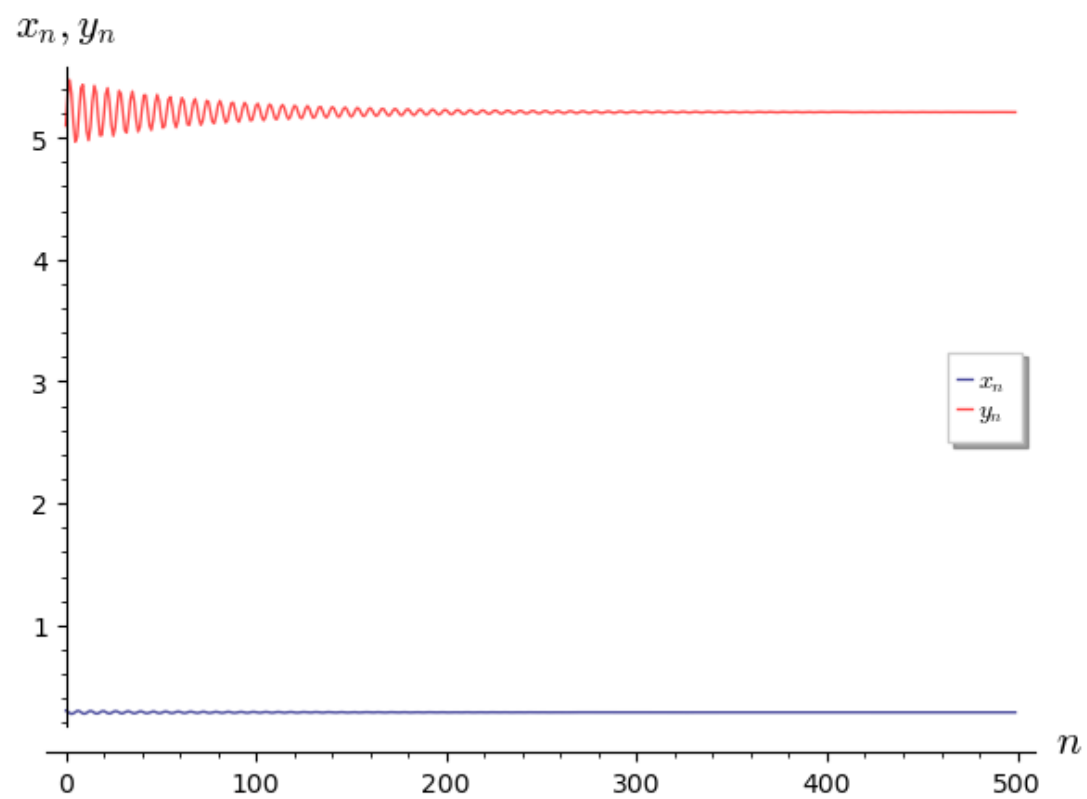




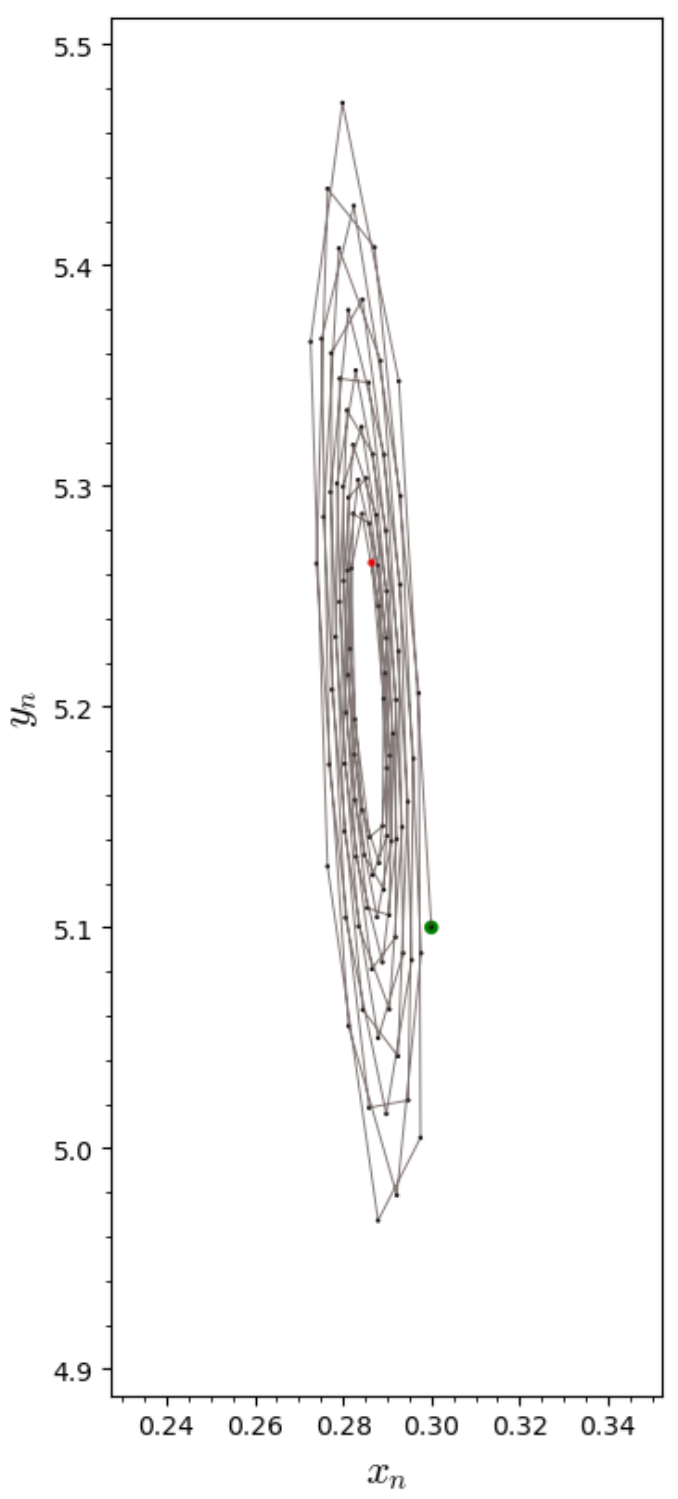



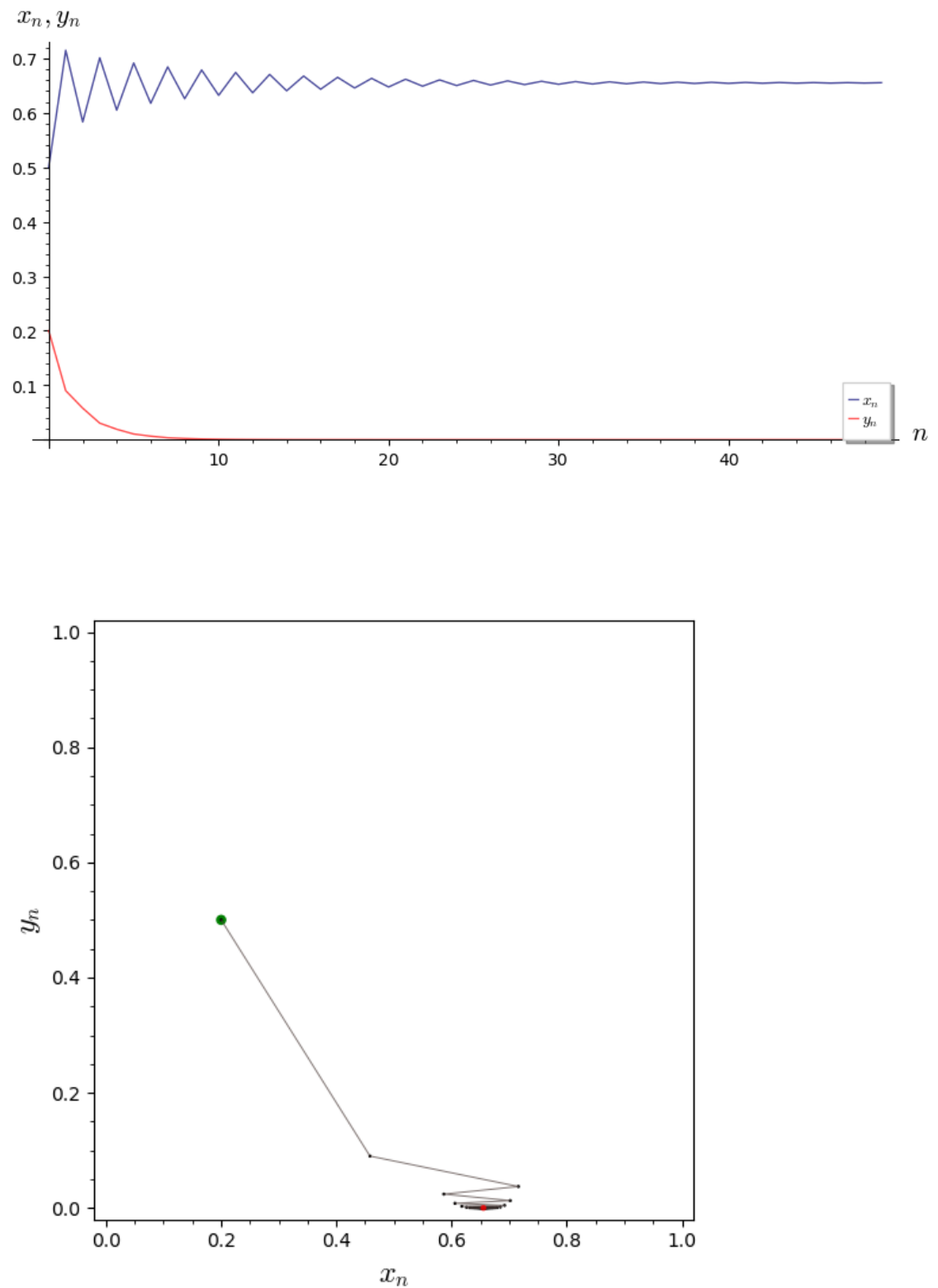

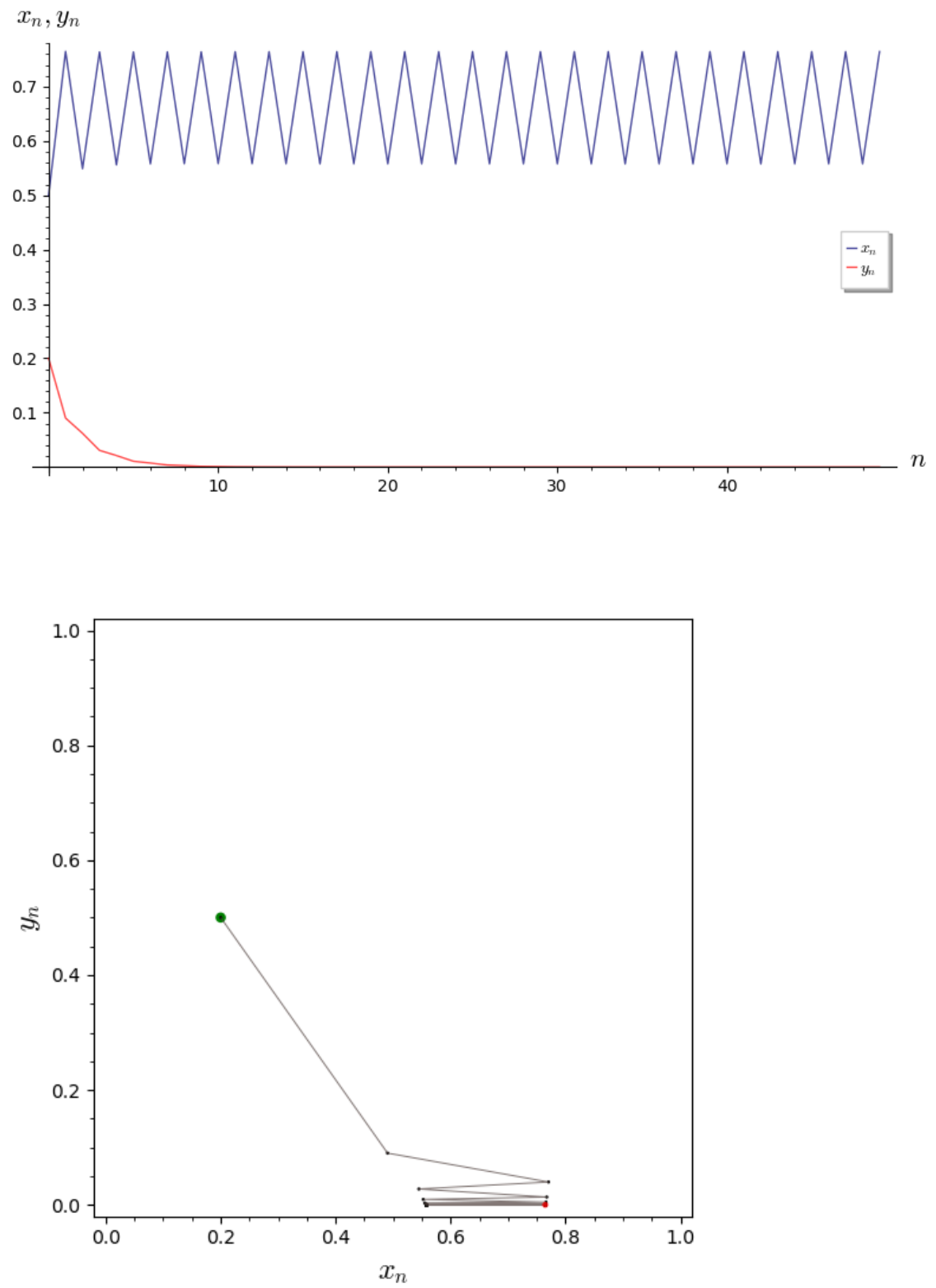

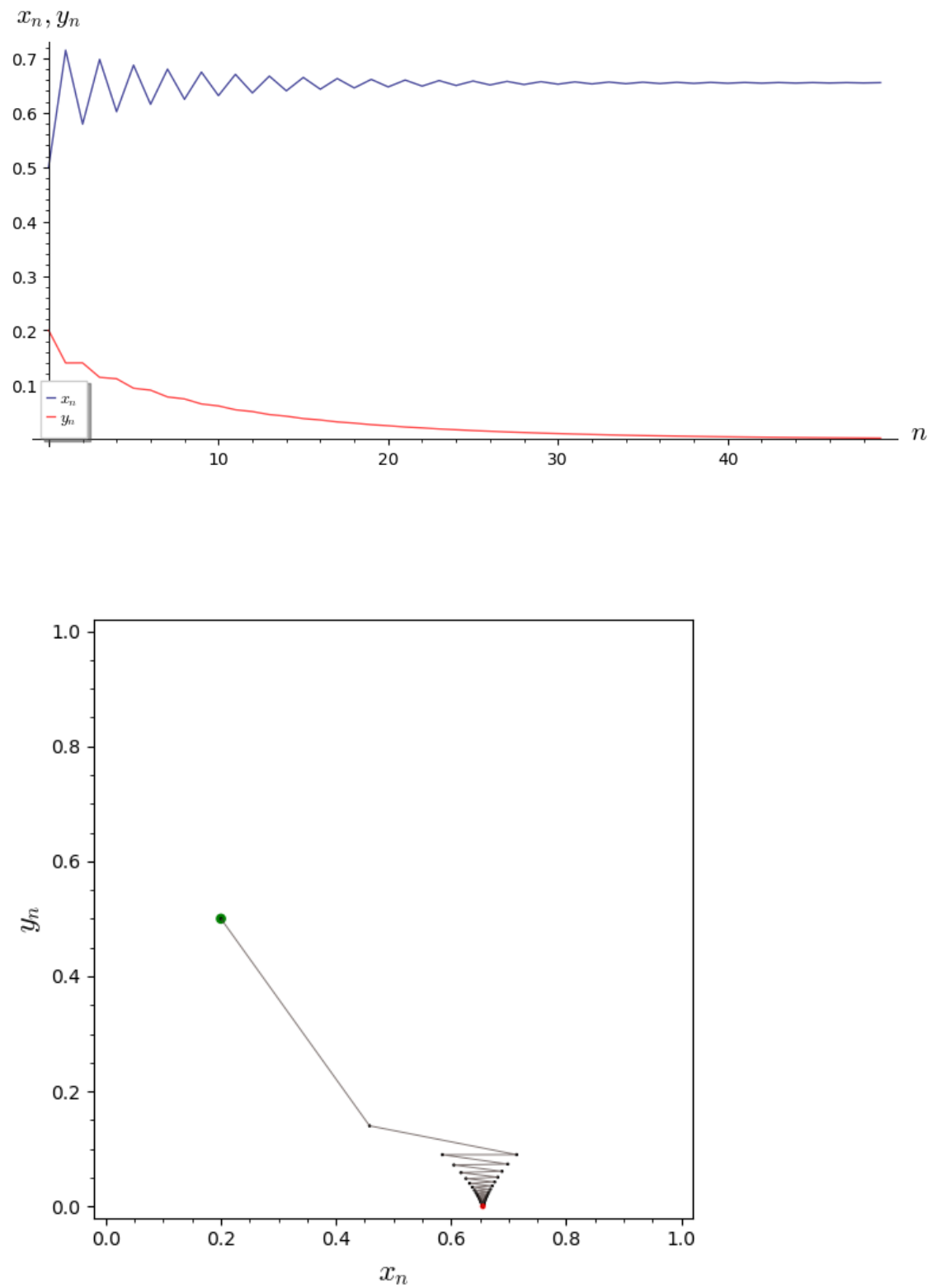

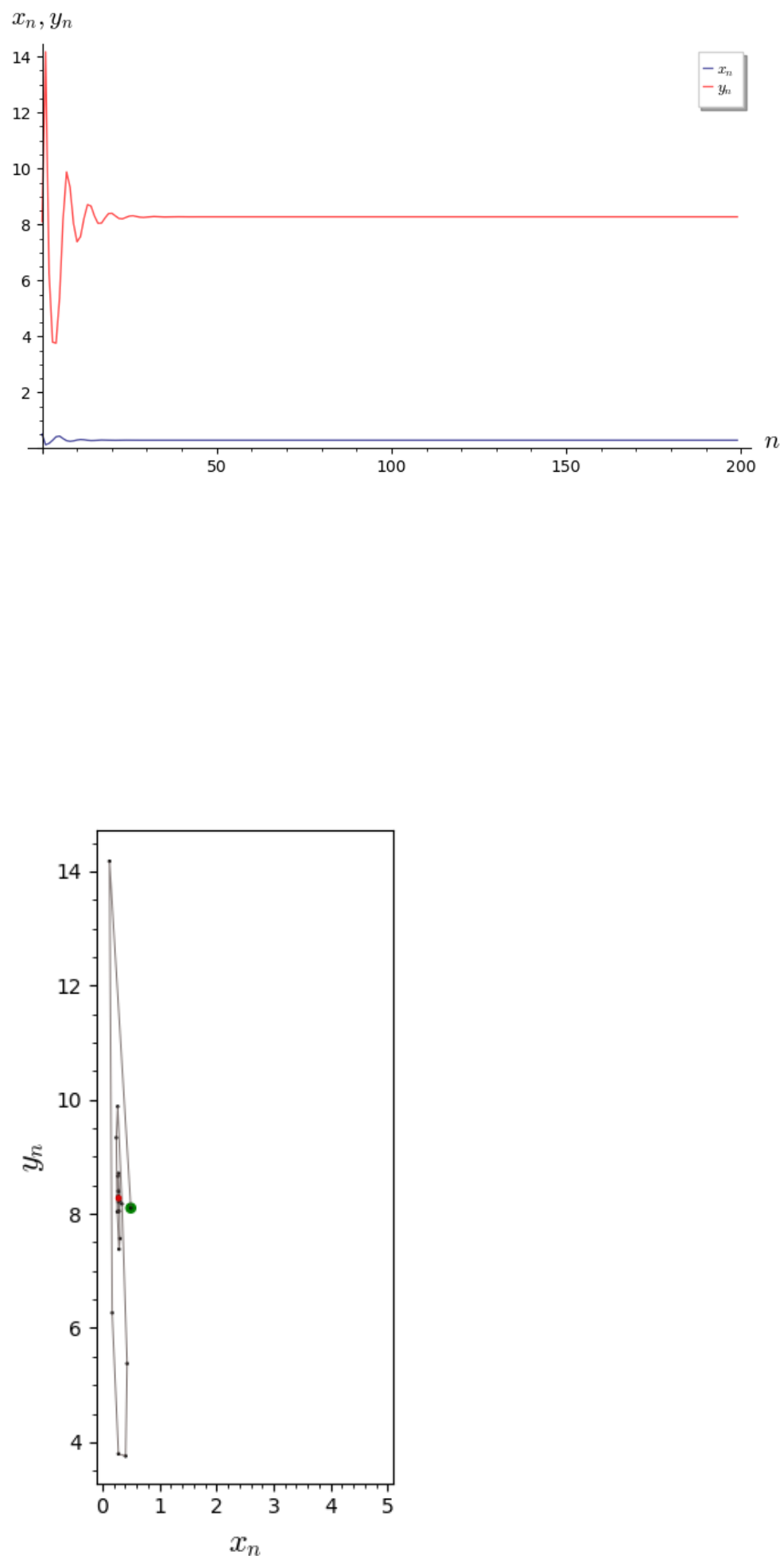

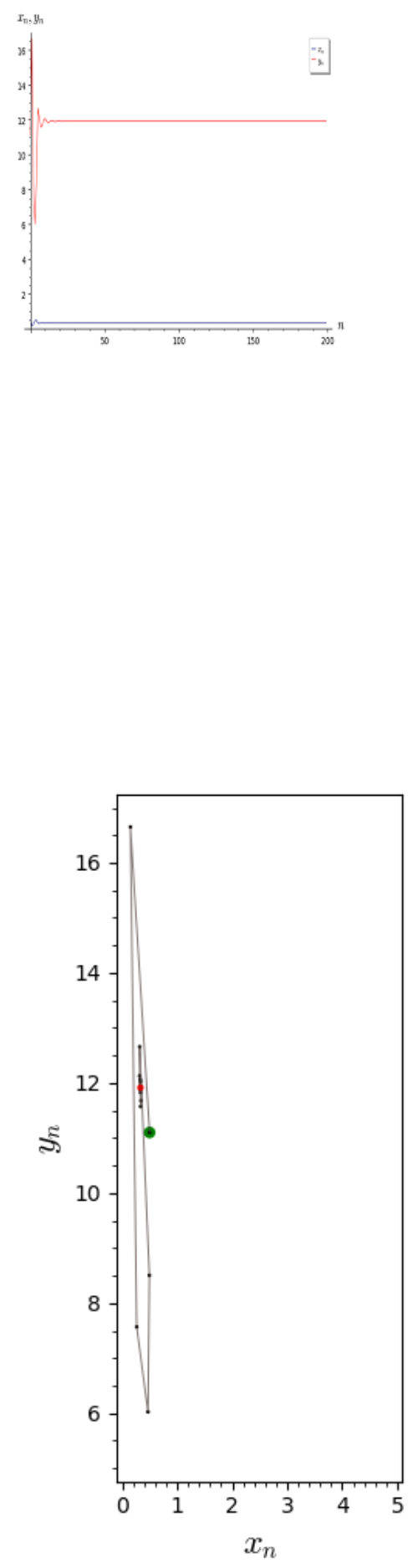

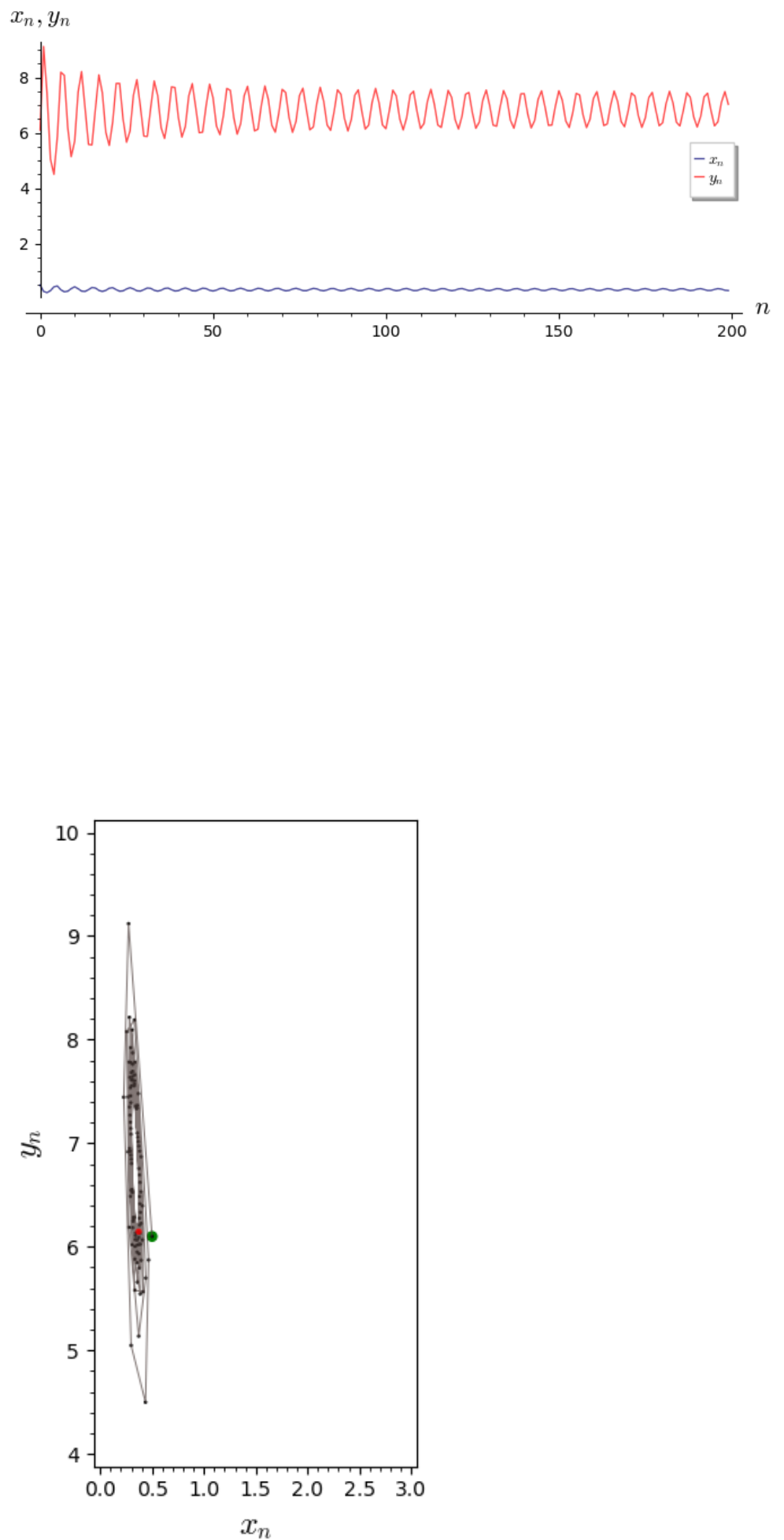

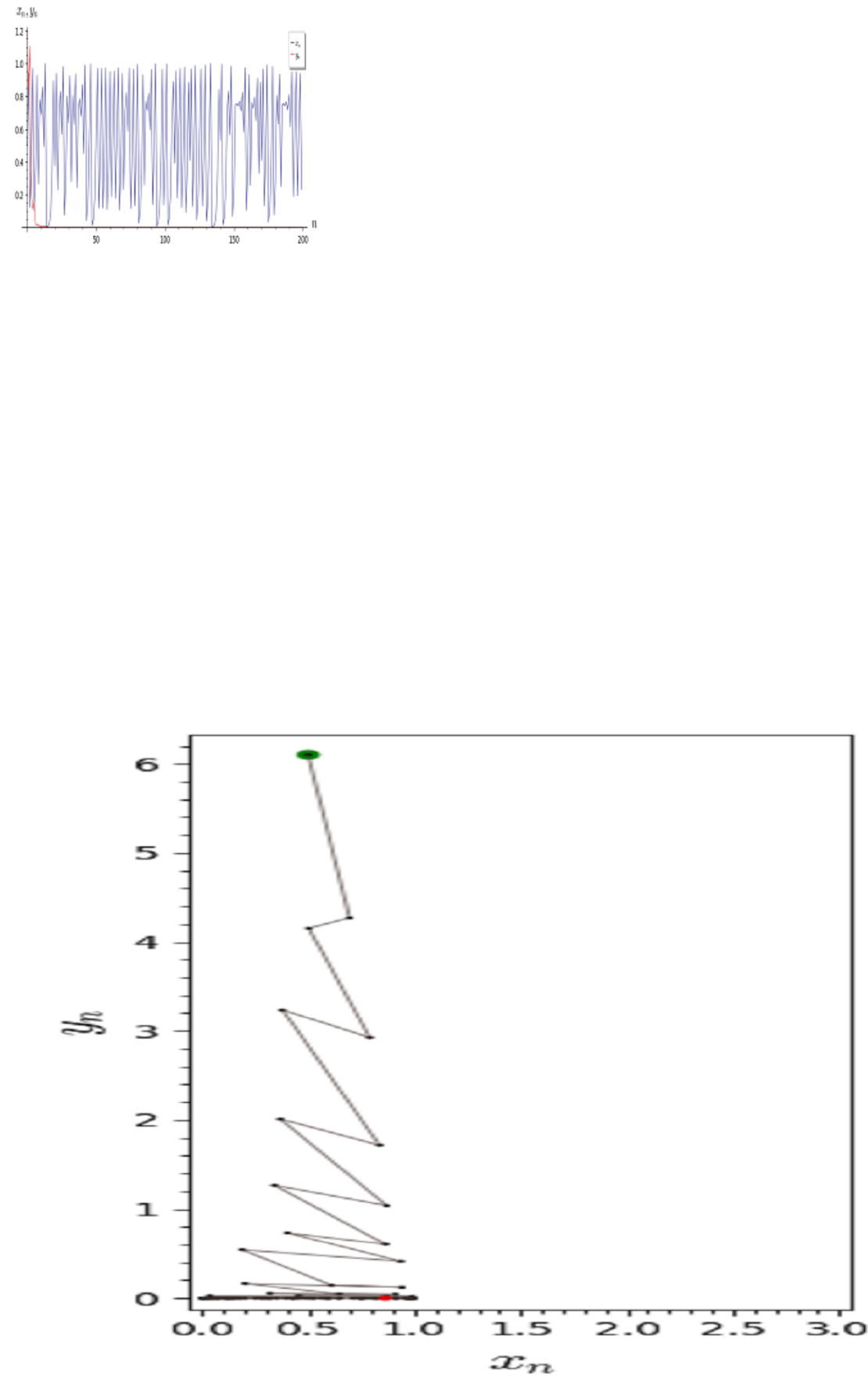